\title{
Stabilization of the stator and rotor flux linkage of the induction motor in the asynchronous electric drives with frequency regulation
}

\author{
Vladimir L. Kodkin, Aleksandr S. Anikin, Aleksandr A. Baldenkov \\ Departement of theoretical fundamentals of electrical engineering, South Ural State University, Russia
}

\begin{tabular}{l}
\hline \hline Article Info \\
\hline Article history: \\
Received Jul 11, 2019 \\
Revised Nov 8, 2019 \\
Accepted Dec 3, 2019 \\
\hline
\end{tabular}

Keywords:

Mathematical modeling Positive feedback

Rotor and stator flux linkage

Scalar control

Variable frequency drive

Vector control

\begin{abstract}
The article is a continuation of the authors' work in research, mainly experimental, asynchronous electric drives with frequency regulation (AED FR) of hoisting-and-transport mechanisms, in which for constructive, operational and other reasons it is difficult to install additional sensors, for example encoders. The results of the analysis of the dynamics of AED FR with two types of sensorless control: vector and scalar are presented in this article. The study was conducted by mathematical modeling in the Simulink application of the MatLab software using standard control system models. The processes of sequential acceleration of the engine to fixed speeds with overload and load shedding on each of them were simulated. At the same time, the speed and effective values of the flux linkages of the rotor and stator and the stator current were monitored, by which the dynamics and efficiency of each type of control were evaluated. As in experimental studies, the dynamic and efficiency of a more stable scalar control was significantly improved by the use of dynamic positive feedback on stator current.
\end{abstract}

This is an open access article under the CC BY-SA license.

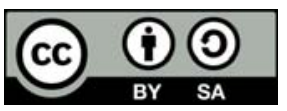

\section{Corresponding Author:}

Aleksandr S. Anikin,

Departement of theoretical fundamentals of electrical engineering,

South Ural State University,

76, Lenin prospekt, Chelyabinsk, Russia. 454080

Email: anikinas@susu.ru

\section{INTRODUCTION}

In recent years, a group of engineers at the South Ural State University (SUSU), headed by Prof. Kodkin V.L. has carried out research on the dynamics of asynchronous electric drives with frequency control (AED FC). Operating experience of such drives shows that it is far from always possible to obtain the required static and dynamic characteristics using only standard control algorithms incorporated in the frequency converter. The research directions were formed based on the results of a theoretical analysis of the basic equations of AED FC, but the main results were obtained during experiments and modeling. This is due to the fact that the AED FC equations contain many assumptions and simplifications, the significance of which is very difficult to estimate theoretically.

The results of the experiments are presented in the articles published in Russian and foreign publications [1, 2]. ATV32 and ATV71 frequency converters from Schneider Electric were used as basic equipment. The main result should be considered the worst drive dynamics with sensorless (on speed) vector control as compared with a scalar control drive, containing corrective dynamic positive feedback on the stator current (DPF) [3, 4]. This feedback includes a dynamic link that provides the necessary gain factors for the 
corrective feedback in the low frequency range without disturbing the stability of the drive. The limited stability of the drive does not allow standard IR and s-compensations to effectively solve their problems.

\section{PROBLEM DEFINITION}

VFD research using the Matlab / Simulink package is devoted to a large number of works. The main part of them analyzes and improves the dynamic characteristics of such systems [5-8], and some of them are equipped with sensorless control $[9,10]$. A lot of work is devoted to improving the energy efficiency of converters in AED FR [11-13] However, the models of electric motors used in them and the models of motors incorporated in the control system are built with the same assumptions. In this regard, there are no such issues in their concordant work. However, no one disputes the presence of these inaccuracies and assumptions [14-20]. The research results raised doubts among colleagues and experts. Basically, these doubts were explained by the provisions "it is known ...", "it's acceptable to consider ...", "we all know ...", "It is known that vector control is better ...", etc.

Reports at conferences, as a rule, for organizational reasons do not allow to sort out the details of the research and, therefore, a number of presentations, including at conferences in Russia, in the USA, in Germany and in China, they failed to convince skeptics. In this regard, February 14, 2019 Professor V.L. Kodkin A detailed report was made as part of a traditional seminar at the National Research University of Information Technologies, Mechanics and Optics, St. Petersburg, Russia. Such seminars are conducted under the guidance of Professor A. Kozyaruk. Within their framework, leading scientists of Russia in the field of electric drive give an assessment of modern research.

During the discussion, colleagues agreed with the main results of the research. They clarified that the conclusions made are true, first of all, for sensorless vector control, which is used in most frequency converters (Schneider Electric, Danfoss, Vacon, etc.) and therefore, the studies have a great practical meaning. One of the leading scientists in this field A. Usoltsev. suggested the advantages of the proposed correction scheme: the DPF, which does not cause instability due to the dynamic link, provides deep stabilization of the magnetic coupling of the rotor, which plays a major role in the formation of the torque of an asynchronous short-circuited electric motor. According to A. Usoltsev, the authors can verify these results by modeling the processes in AED FR. It should be noted that such an assumption very logically explains all the results. Therefore, after this seminar, the task was to conduct a comparative simulation of asynchronous electric drives with different control systems. In the course of this simulation, in addition to the speed and current of the motor, it is also necessary to control its magnetic flux. The results of this work are given in this article.

\section{SOLUTION}

The simulation was carried out in the Simulink application of the MATLAB software. As in the previous studies of the authors, for the first version, AED FR was performed using the standard model of the VFD with vector control [21-23] Figure 1. The author of the model is Professor Hoang Le-Huy, Professor at the Department of Electrical Engineering and Computer Engineering, Laval University, Quebec, Canada.
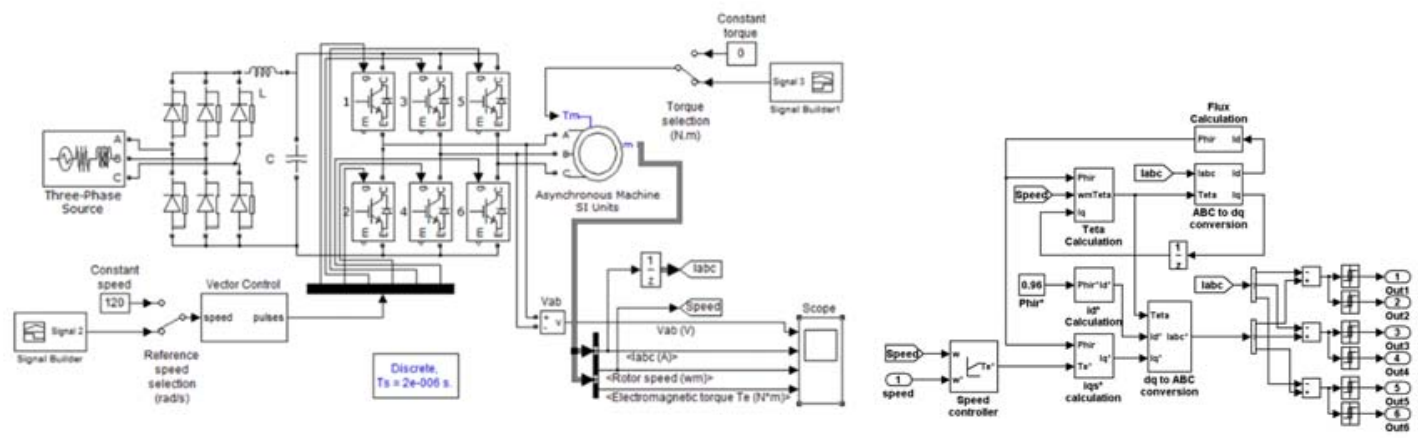

Figure 1. Model of VFD with vector control and the module "Vector control" 
To study the scalar control system Figure 2, the model of Professor Louis Desantes (Louis-A. Dessaint) from the state engineering school (École de technologie supérieure) in Montreal (Quebec, Canada) was used [24, 25]. To increase the efficiency of the formation of the electromagnetic torque, positive feedback on the root mean square (rms) value of the stator current was introduced into the control system Figure 3.

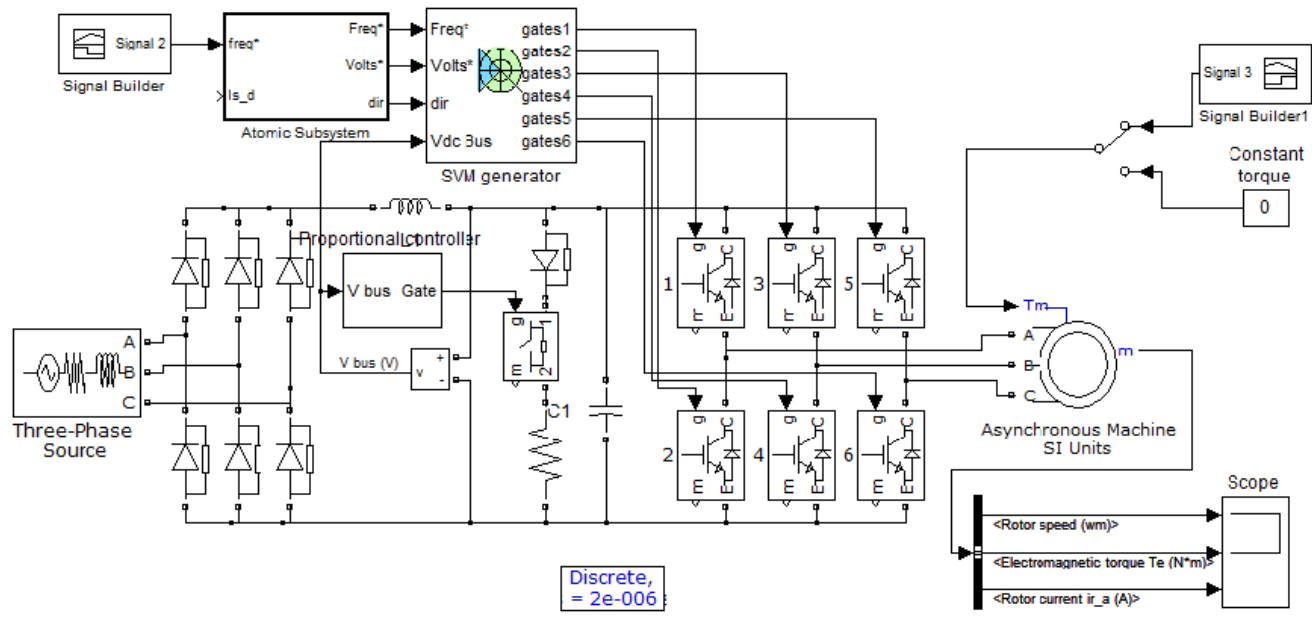

Figure 2. Scheme of scalar control model

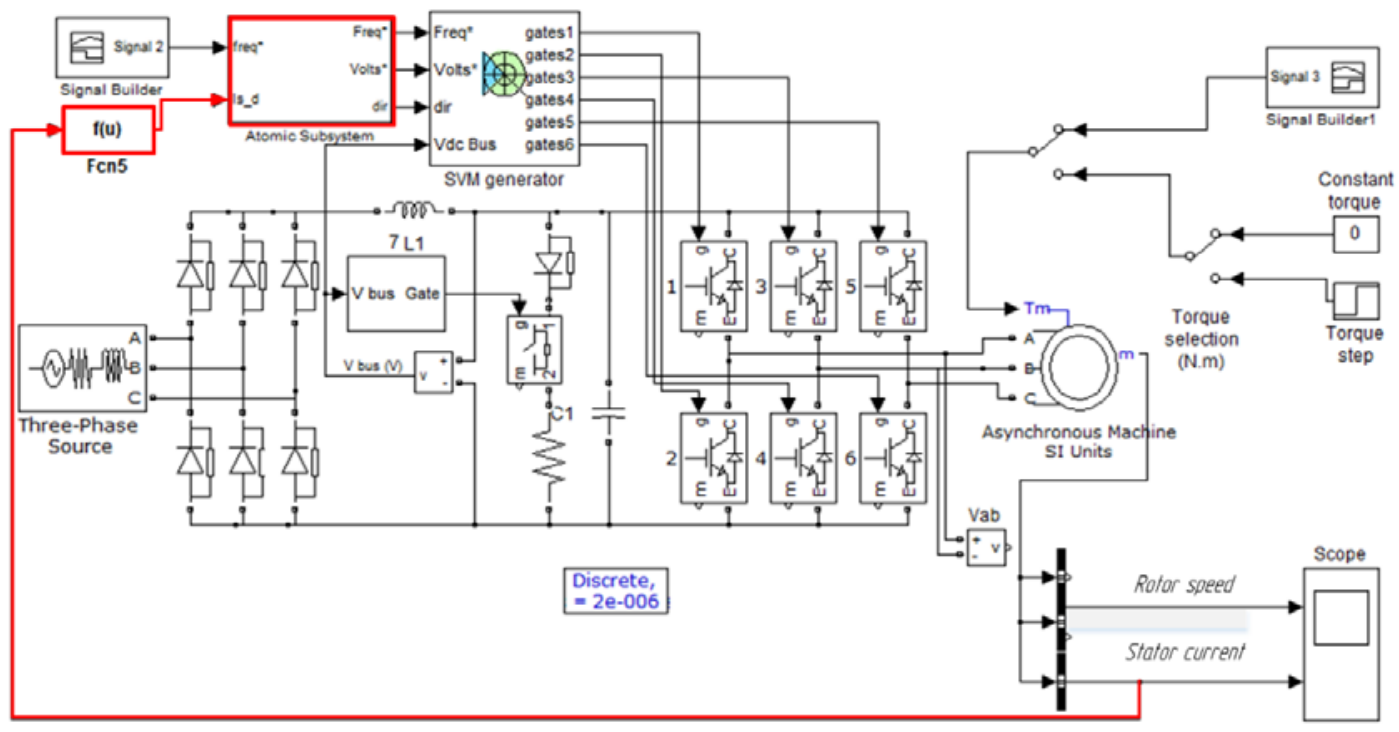

Figure 3. Scheme of a scalar control model with positive feedback

Simulation of processes of sequential acceleration to speeds corresponding to the supply voltage frequency of $10-20-30-40-50 \mathrm{~Hz}$ was carried out, at each speed of rotation a load was drawn. The angular velocity of the motor shaft and the rms values of the rotor and stator flux linkages and the stator current were controlled. The rms values were calculated from the projections on the $d$ and $q$ axes of the corresponding signals, which are available for measurement in the model of an asynchronous electric motor. The last signal is required to evaluate the efficiency of the drive. The simulation results of scalar control without feedback are shown in Figure 4, of the vector control with a single speed contour (without a flux linkage contour) - in Figure 5 and scalar control with positive feedback on the rms value of the stator current

Stabilization of the stator and rotor flux linkage of the induction motor... (Vladimir L. Kodkin) 
and a dynamic link - in Figure 6. At the same time, special attention was paid to the change in the stator and rotor fluxes at the moment of loading. The deviations of the rotor and stator under load from the values at idle for different frequencies of the supply voltage with different control algorithms are shown in Tabel. 1.

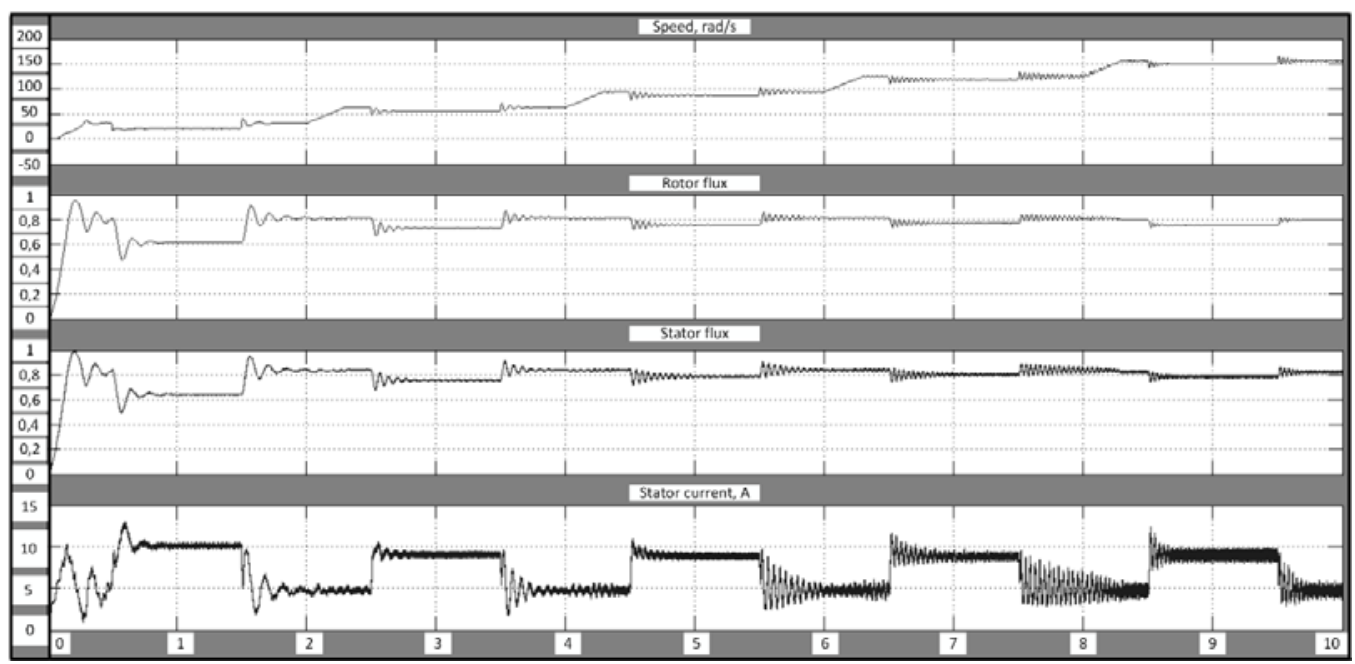

Figure 4. Modelling processes in an asynchronous electric drive with scalar control without feedback

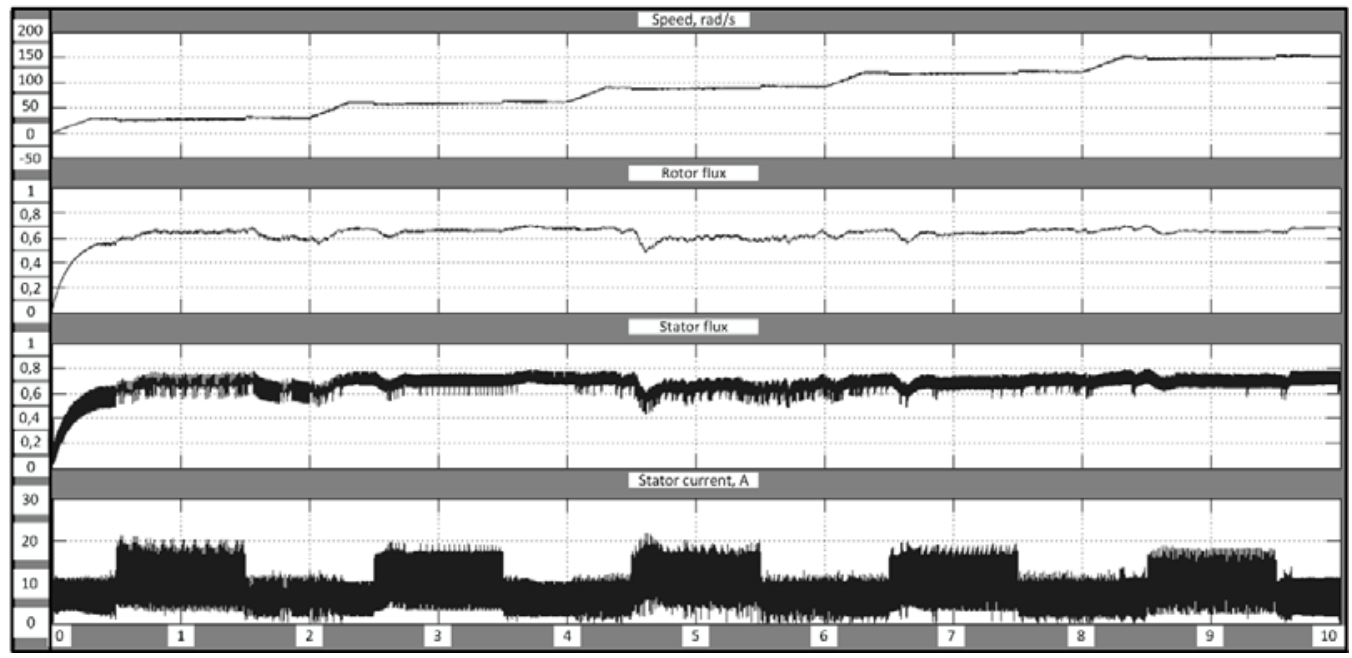

Figure 5. Modelling processes in an asynchronous electric drive with vector control system

Table 1. The deviations values of the rotor and stator flux under load for different frequencies of the supply voltage and control system

\begin{tabular}{cccccc}
\hline \multirow{2}{*}{ Control system } & \multicolumn{5}{c}{ Maximum deviations of rotor / stator fluxes, $\mathrm{V} \cdot \mathrm{s}$} \\
& $10 \mathrm{~Hz}$ & $20 \mathrm{~Hz}$ & $30 \mathrm{~Hz}$ & $40 \mathrm{~Hz}$ & $50 \mathrm{~Hz}$ \\
\hline \multirow{2}{*}{ Scalar control without feedback } & $-0,2 /$ & $-0,09 /$ & $-0,05 /$ & $-0,03 /$ & $-0,04 /$ \\
& $-0,2$ & $-0,11$ & $-0,05$ & $-0,03$ & $-0,03$ \\
\multirow{3}{*}{ Vector control with a single speed contour } & $0,06 /$ & $-0,03 /$ & $-0,05 /$ & $-0,03 /$ & $-0,03 /$ \\
& 0,1 & $-0,04$ & $-0,06$ & $-0,03$ & $-0,03$ \\
\multirow{2}{*}{ Scalar control with DPF } & $-0,1 /$ & $-0,03 /$ & $-0,03 /$ & $-0,03 /$ & $-0,04 /$ \\
& $-0,1$ & $-0,03$ & $-0,03$ & $-0,03$ & $-0,02$ \\
\hline
\end{tabular}




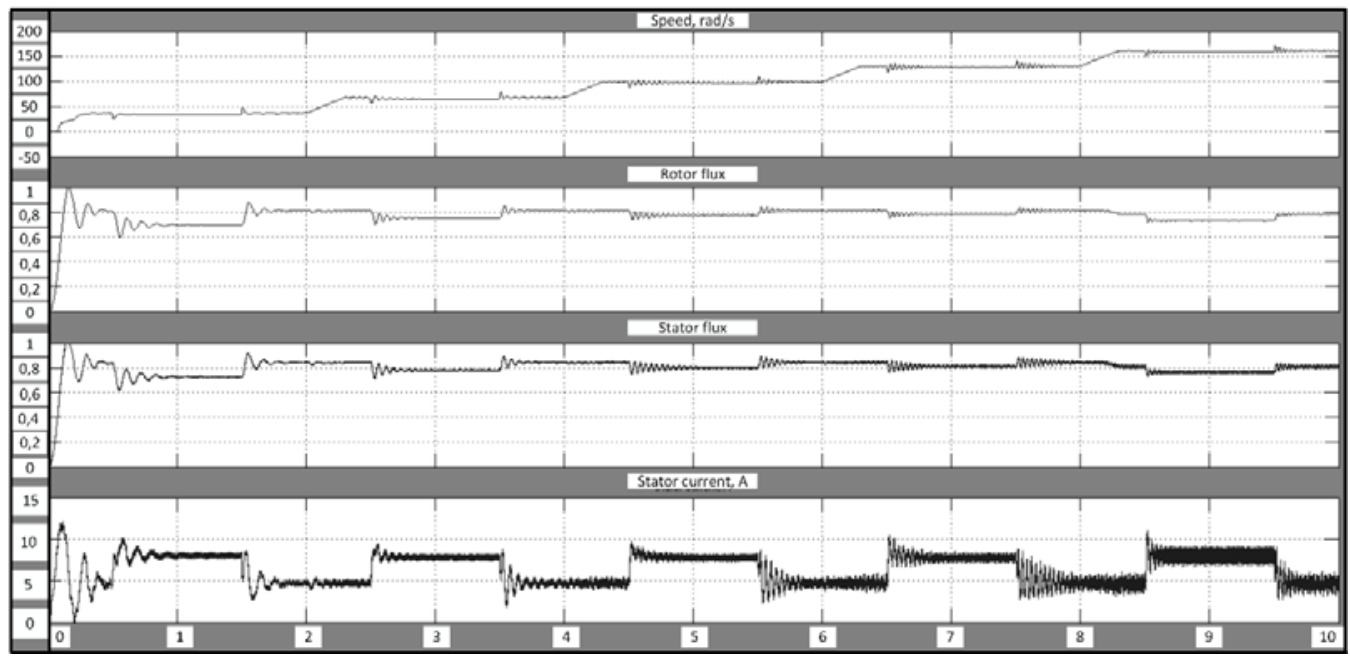

Figure 6. Modelling processes in an asynchronous electric drive with scalar control without feedback

In scalar control, the maximum possible value of standard IR-compensation was established (which maintains stability). At the same time, the scatter of stator and rotor fluxes at low speed (30 rad $/ \mathrm{s})$ is in the region of $0,2 \mathrm{~V} \cdot \mathrm{s}$, and decreases to $0,1 \mathrm{~V} \cdot \mathrm{s}$ with an increase in speed to nominal $(157 \mathrm{rad} / \mathrm{s})$. With the introduction of the DPF, the flow deviations during accelerations and load surges do not exceed $0,1 \mathrm{~V} \bullet \mathrm{s}$. With vector control, the mean value of the flow deviations is also $0,1 \mathrm{~V} \cdot \mathrm{s}$, but at the same time, there is a high-frequency component in the stator flow. Attention should be paid to the stator currents, which are the greatest in vector control and minimal in DPF Tabel 2. Thus, the simulation clearly showed that in the electric drive with DFT the flow stabilization is practically at the same level as the vector control.

Table 2. The values of stator currents under load for different frequencies of the supply voltage and control system

\begin{tabular}{cccccc}
\hline Control system & \multicolumn{5}{c}{ Stator current under load, A } \\
& $10 \mathrm{~Hz}$ & $20 \mathrm{~Hz}$ & $30 \mathrm{~Hz}$ & $40 \mathrm{~Hz}$ & $50 \mathrm{~Hz}$ \\
\hline Scalar control without feedback & 10 & 8 & 7,5 & 7,5 & 9 \\
Vector control with a single speed contour & 14 & 13 & 12 & 13 & 13 \\
Scalar control with DPF & 8 & 7 & 7 & 7,5 & 8,5 \\
\hline
\end{tabular}

In addition, processes in a drive with vector control with a speed error of 2 and $4 \%$ are simulated Figure 7,8 . The simulation results are very visual. With the introduction of an error rate of $2 \%$ into the signal Figure 7, the control loses operation at a speed corresponding to the frequency of the stator voltage of $40 \mathrm{~Hz}$, and with an error of $4 \%-30 \mathrm{~Hz}$ Figure 8 . Large stator currents are a very serious problem for drives in transport and power complexes, where the load is non-deterministic.

Thus, the modeling of processes with control of flux linkage fully confirmed the assumption of Professor A. Usoltsev, and explained the reason for the significant advantages of the proposed DPF over traditional algorithms. You can implement this correction, without any changes in the circuits and algorithms of standard frequency converters, on a programmable logic controller. This makes the widespread use of the proposed correction available in almost any electric drive. The authors are grateful to the seminar at the National Research University of Information Technologies, Mechanics and Optics, and especially to Professor A. Usoltsev, who is considered the author of the idea of this simulation. 


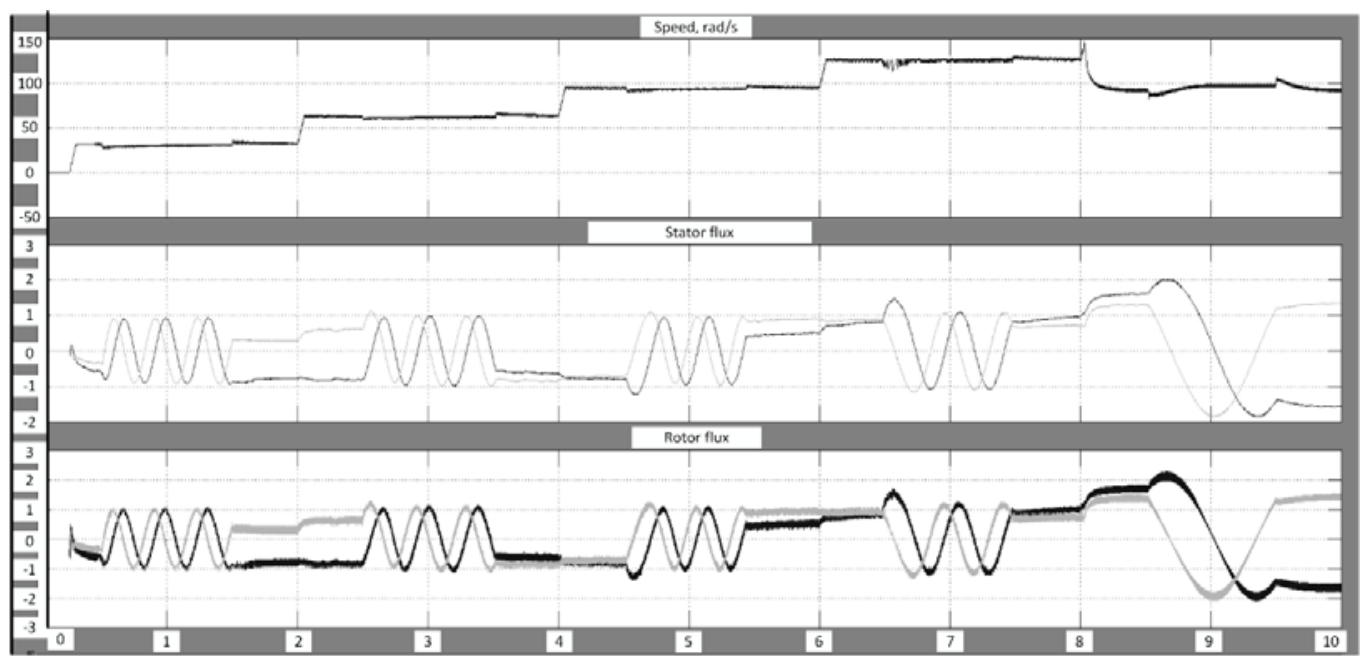

Figure 7. Vector control with speed error of $2 \%$

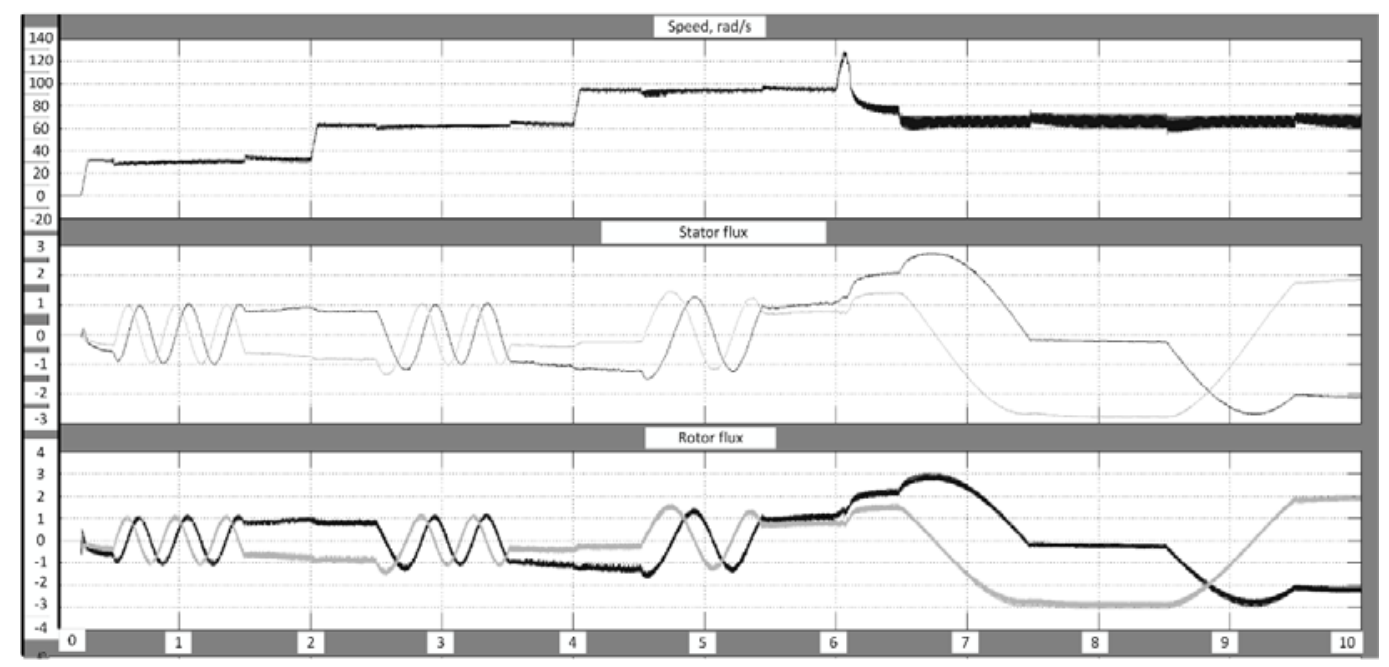

Figure 8. Vector control with speed error of $4 \%$

\section{CONCLUSIONS}

The conducted simulation of AED FR with scalar control and positive feedback on the stator current showed that this correction allows stabilizing the flux linkage of the rotor and stator in an electric machine. This ensures a more efficient formation of the electromagnetic moment at lower stator currents and less absolute slip. In turn, such a correction improves the static and dynamic characteristics of an asynchronous electric drive with frequency control, and makes it possible to use middle-class technical-economic frequency converters in complex industrial mechanisms with high demands on the static and dynamic characteristics of the drive.

\section{REFERENCES}

[1] Kodkin V.L., "Experimental research of asynchronous electric drive with positive dynamic feedback on stator current" International conference on industrial engineering Applications and Manufacturing, ICIEAM 2017 Proceedings.-2017.

[2] Anikin A.S., "Dynamic positive coupling in asynchronous electric drives with frequency control,"Priorities of world science: experiment and scientific discussion Materials of the 8th international scientific conference. Scientific and Publishing Center Otkrytie. North Charleston, SC, USA, pp. 17-18, - pp.119-124, June 2015. 
[3] Kodkin, V. L., A.S. Anikin, A.A. Baldenkov, "The dynamics identification of asynchronous electric drives via frequency response," International Journal of Power Electronics and Drive Systems (IJPEDS), Vol. 10, No. 1, pp. 66-73, 2019.

[4] Kodkin, V. L., A.S. Anikin, A.A. Baldenkov, "Performance identification of the asynchronous electric drives by the spectrum of rotor currents," International Journal of Power Electronics and Drive Systems (IJPEDS), Vol. 10, No. 1, pp. 211-218, 2019.

[5] Alekseev V. V, Emel'yanov A. P, Kozyaruk A. E., "Analysis of the dynamic performance of a variable-frequency induction motor drive using various control structures and algorithms," Russian Electrical Engineering, Vol. 87. No. 4, pp. 181-188, 2016.

[6] Alekseev V. V, Vershinin V. I, Vasiliev B. Yu., "Determination of the parameters of flux linkage vectors in electric drives with vector control," Notes of the Mining Institute, Vol. 196. pp. 222-225, 2012.

[7] Kvashnin V.O, \& Cherednik Yu. N, "Construction of a mathematical model of an induction motor in synchronous axes with temperature compensation for changes in rotor flux linkage," Electrotechnical and Computer Systems, vol. 3, No. 79, pp. 256-257, 2011.

[8] Alekseev V. V, \& Kozyaruk A. E. "Comparative analysis of models for systems of an automated asynchronous drive with vector control," Russian Electrical Engineering, Vol. 84, No. 12, pp. 702, 2013.

[9] Vasiliev B. Yu, \& Kozyaruk A. E. "Increasing the efficiency of asynchronous electric drives with direct torque control," Bulletin of SUSU. Ser. Energy, Vol. 13, No. 2. pp. 75-84, 2013.

[10] Moustafa Zair, \& Abdeldejbar Hazzab," MRAS speed sensorless vector control of induction motor drives using predictive adaptation mechanism," International Journal of Power Electronics and Drive Systems (IJPEDS), Vol. 9, No. 4, pp. 1523-1533, 2018.

[11] Muldi Yuhendri, Ahyanuardi Ahyanuardi, Aswardi Aswardi., "Direct torque control strategy of PMSM employing ultra sparse matrix converter," International Journal of Power Electronics and Drive Systems (IJPEDS), Vol. 9, No. 1, pp. 64-72, 2018.

[12] Kozyaruk A. E, \& Rudakov V. V, "Modern and perspective algorithmic maintenance is frequency-regulated electric drives," SPEC. Saint Petersburg, 2004.

[13] Othmane Salama, Abdelmoumen Tabyaoui, Mohamed Benchagra,. "Control methods on three-phase power converters in photovoltaic systems," International Journal of Power Electronics and Drive Systems (IJPEDS), Vol. 9, No. 4, pp. 1851-1865, 2018.

[14] Yeshin E. K., "Electromechanical systems of multimotor drives," Modeling and controlling, State Technical University of Kuzbass, pp. 247, 2003.

[15] Research of automatic electric drives, electrical machines and valve inverter: thematic digest of scientific works under edition of LifanovV.A., Levintov S.D.-Chelyabinsk: CPI, 160, 1990.

[16] Figaro B. I, \& Pavlyachik L. B, "Regulating electrical drives of alternating-current," Misnk: Technoperspectiva, pp. 363, 2006.

[17] Sokolovsky G. G., "Electric drives of alternating current with frequency regulation," $M$ : ACADEMIA, pp. 267, 2006.

[18] Usoltsev A. A, Vorobyov N. V, Feshin B. N., "Methodology for the analysis of electromagnets of processes in subsystems of an automated electric drive," Automation and Informatics, Vol. 2, No. 35. pp. 50-53, 2014.

[19] Usoltsev A. A., "Determination of the parameters of the asynchronous motor model according to the reference data," News of universities, Instrument making, vol. 51, No. 10, pp. 35-41, 2008.

[20] Ilyina A. G, \& Usoltsev A. A, "Optimal motion control during positioning and its modeling in the MathLab," Simulink environment, Instrument making, vol. 51, No. 6, pp. 63-68, 2008.

[21] Hoang Le-Huy, "Modeling and simulation of electrical drives using MATLAB/Simulink and Power System Blockset", IECON'01. 27th Annual Conference of the IEEE Industrial Electronics Society.

[22] Marc Perron; Hoang Le-Huy, "Full Load Range Neural Network Efficiency Optimization of an Induction Motor with Vector Control using Discontinuous PWM”, IEEE International Symposium on Industrial Electronics, 2006.

[23] Hoang Le-Huy; G. Sybille, "MATLAB/Simulink and PSPice as modelling tools for power systems and power electronics", Power Engineering Society Summer Meeting, 2000.

[24] Louis-A. Dessaint, \& Roger Champagne, "Real-time simulation of electric drives," Mathematics and Computers in Simulation, vol. 63, No. 3-5, pp. 173-181 2003.

[25] Louis-A. Dessaint, \& Kamal Al-Haddad, "Modelling and simulation of electric machines, converters and systems," Mathematics and Computers in Simulation, vol. 63, No. 3-5, pp. 135-143, 2003. 